Article

\title{
Opportunities and Challenges for Meeting the UN 2030 Agenda in the Light of Global Change-A Case Study of Swedish Perspectives
}

\author{
Karin Eliasson *(D), Victoria Wibeck ${ }^{(D)}$ and Tina-Simone Neset \\ Department of Thematic Studies-Environmental Change, Centre for Climate Science and Policy Research, \\ Linköping University, 58183 Linköping, Sweden; victoria.wibeck@liu.se (V.W.); tina.neset@liu.se (T.-S.N.) \\ * Correspondence: karin.eliasson@liu.se
}

Received: 13 August 2019; Accepted: 19 September 2019; Published: 24 September 2019

check for updates

\begin{abstract}
This study explores how geopolitical aspects can affect actors' sense of agency to achieve the UN 2030 Agenda for Sustainable Development and its ambition to transform the world sustainably by studying the linkages between global change and the 2030 Agenda as described by Swedish change agents. Sweden has a self-declared ambition for leadership in the 2030 Agenda. The world's high-income countries, including Sweden, have been given a specific responsibility to achieve the Sustainable Development Goals. The results of this focus group study show that the geopolitical landscape encompasses a multitude of actors and roles whose relationships are filled with tension, creating dichotomies between them. The analysis indicates that Sweden is assessed to be dependent on functioning ecosystems, both locally and globally, as well as causing global environmental change. Two narratives have emerged: (i) the narrative of the 2030 Agenda, referring to deliberate societal transformations that can be controlled and steered, and that have a direction; and (ii) the narrative of geopolitics, indicating perceptions of emergent transformations that appear uncontrollable, drifting aimlessly towards an unknown future. These narratives might influence the understanding of societal transformations, and need to be considered in the facilitation of platforms for deliberative transformations or responses to emerging transformations.
\end{abstract}

Keywords: UN 2030 Agenda; sustainable development goals; sustainability; societal transformations; geopolitics; environmental change; Sweden; focus groups; sense-making

\section{Introduction}

The United Nations' 2030 Agenda for Sustainable Development is an agenda for "transforming our world" until 2030 [1] (p. 1). Through its 17 interlinked goals and 169 targets, the 2030 Agenda aims for a "quantum leap" approach to societal transformations towards sustainability [2], presuming rapid transformations across societies. Unlike their predecessor, the Millennium Development Goals, the ambitions for the Sustainable Development Goals (SDGs) span the globe, involving high- as well as low- and middle-income countries in taking "the bold and transformative steps which are urgently needed to shift the world onto a sustainable and resilient path" [1] (preamble).

Deliberate efforts to instigate and govern societal transformations to achieve the SDGs unfold against a backdrop of emergent transformations affecting everyday life and societal organisation around the world, such as global environmental change and the accelerated amalgamation of technology in the digital, biological, and physical realms-from artificial intelligence and machine learning to nanotechnology and gene editing [2]. Unequal distribution of wealth and power, unemployment, global health threats, natural disasters, forced displacement of people, natural resource depletion, environmental degradation and climate change have been emphasised by the United Nations (UN) as major challenges to sustainable development—challenges that the SDGs aim to address [1]. 
In this rapidly shifting landscape, geopolitical uncertainties related to environmental change and human security abound. Cohen [3] points to the increasing influence of environmental change on geopolitics, while Dalby [4] argues that, in the future, geopolitics will concern energy consumption, food systems, urban planning and infrastructure rather than war plans. The scientific and policy discourse has shifted from only dealing with state and national security to now also including human and environmental security $[5,6]$ which has implications for how society deals with questions such as who is in need of being secured, from what threat, by what actors and by what means [7-9]. For instance, in the field of securitization of water resources, geopolitical uncertainty is added to model and data uncertainty [10-12]. Climate security is another example where the identification of linkages between climate change and violent conflict is difficult, although recent studies indicate that current climatic changes could exacerbate conflicts $[13,14]$ and that the risk of future conflicts due to intensifying climate change might increase [14]. De Châtel [9] hints to this complexity of security, geopolitics and environmental change when discussing the interactions of a series of social, political and economic factors that, alongside severe drought, led to violent conflict in Syria.

Geopolitics has been described and defined in various ways by different scholars [3,15-22]. Cohen applies the definition "interactions between, on the one hand, geographical settings and perspectives and, on the other, political processes" [3] (p. 16), in which interactions are understood as dynamic processes where people, goods and ideas that circulate between human and natural environments, while Koopman argues that "geopolitics means a focus on peace(s) across places, including the place of the body" [15] (p. 275). Tuathail states that "geopolitics does not have a singular, all-encompassing meaning or identity. Its discourse is a culturally and politically varied way of describing, representing and writing about geography and international politics" [16] (p. 3).

After the Cold War period, which was characterised by a static equilibrium and, thereby, a kind of stable geopolitical situation due to the deadlock between the United States (US) and the Soviet Union, the emergence of a more complex and flexible situation has been proposed [3]. Several scholars suggest that power has become more diffused and decentralised, resulting in more fluid geopolitical structures, with, for example, increased power of metropolitan areas and transnational megalopolises, which act as independent economic actors globally $[3,23,24]$. This development, together with the increased importance of global governmental bodies and non-governmental organisations as well as the globalisation of both economy and information, has led to discussions of the end of the national state as a geopolitical actor [3,25-27].

The emerging geopolitical system has been described as polycentric and polyarchic with multiple nodes and links, with current changes occurring at multiple interconnected levels, in an unconcerted manner [3], hence creating an uncertain geopolitical landscape. Changes in both socio-economic and biophysical systems are posing new threats, such as climate change, that are difficult to define and confine $[15,28,29]$.Placing sustainability at the center of security will have great implications for how geopolitics is performed [30].

In an uncertain geopolitical landscape, it is of increasing importance to understand whether and how geopolitical aspects affect the actors' agency to achieve the 2030 Agenda and its ambition to sustainably transform the world. The research literature converges on an understanding of transformation as fundamental, systemic, non-linear change encompassing technology, politics, economics, environment, culture and sense-making [2,31,32]. However, in practice, the concept of societal transformation takes on largely different meanings for different actors across societies, for example, with regard to the pace, scope, goal and governability of transformations [2,33].

This study contributes perspectives on the UN 2030 Agenda in the light of geopolitical uncertainty. The paper draws on the analysis of focus group discussions with Swedish agents of change [34-36], which in this study refers to actors that have the potential to influence societal transformations at a national scale, such as representatives from the business sector, governmental agencies, non-governmental organisations and academia. 
Sweden is a relevant case in point, as it represents one of the high-income countries, and as such has been given a particular responsibility for achieving the SDGs [1]. Furthermore, Sweden explicitly seeks to take directional leadership by leading by example and to engage a multitude of actors [37]. For instance, in advance of COP 21 in Paris in 2015, Sweden launched a government-led initiative under the label of 'Fossil Free Sweden' as a contribution to the Lima-Paris Action Agenda, with the aim of involving non-state actors from e.g., municipalities and businesses in a network showcasing Swedish decarbonisation efforts and inspiring other countries to follow [38]. Moreover, the 2017 Swedish Voluntary National Review of the implementation of the 2030 Agenda stated: "It is the Government's ambition that Sweden will be a leader in implementing the 2030 Agenda-both at home and through contributing to its global implementation" [37] (p. 8). Peace, democracy, a strong economy, collaborative culture, good business climate, the welfare model and gender equality are areas where Sweden considers itself already strong, providing opportunities for spreading solutions for sustainable development [37]. Nonetheless, it should be noted that the country also faces challenges, in particular concerning sustainable consumption and production, with a high per capita consumption, corresponding to a footprint of 6.5 global hectares in 2016 which was ranked number 16 in the world [39].

This study aims to explore how agents of change in Sweden make sense of challenges and opportunities for Sweden in achieving the SDGs under geopolitical uncertainty. The study identifies competing and converging perspectives, as well as potential trade-offs and synergies, that can be of importance for societal transformations towards sustainability. Specifically, the paper used the following set of questions to guide the analysis of the material from three focus groups:

- Which geopolitical actors are identified by the focus group participants and how are their agency, roles and responsibility on the geopolitical stage described?

- What relationships between geopolitical actors are described by the focus group participants?

- What challenges and opportunities do the focus group participants identify for achieving the 2030 Agenda and how are they related to agency, roles, responsibility and relationships on the geopolitical stage?

Through addressing these research questions, the analysis sets out to shed light on Sweden's role as a leader in achieving the 2030 Agenda and societal transformations under geopolitical uncertainty and discuss linkages between environmental change and geopolitics. The focus group methodology and analytical approach used in the study are described in Section 2 and the results of the empirical analysis, in relation to the questions above, are presented in Section 3. In Section 4 the findings are discussed in relation to the aim of the study. The paper ends with concluding remarks in Section 5.

\section{Materials and Methods}

This study formed the first stage of a co-creation process as part of the research programme Mistra Geopolitics (www.mistra-geopolitics.se), involving researchers and stakeholders in various participatory exercises throughout the course of the programme. A semi-structured focus group methodology was chosen for the initial phase of the co-creation process to identify and explore issues that could be relevant for future research $[40,41]$.

The study is theoretically informed by a dialogical approach to sense-making, which acknowledges that humans live in the world of others and that their existence, thoughts and language are thoroughly interdependent with the existence, thoughts and language of others [42-44]. Drawing on a social constructivist framework, the study sees sense-making as a collective and active process where the participants express, shape and at times re-shape beliefs, ideas, opinions and understandings together in interactions [45]. Since focus groups allow the participants to build on each other's understandings, the method arguably generates a broader set of ideas and associations compared to, for example, individual interviews [44]. 
This study included 17 informants in total (see Table 1). Each informant participated in one of three focus group sessions. Upon invitation, the participants were informed that the topic of the focus groups would be "the future of Sweden and Swedish actors in a changing geopolitical landscape".

Table 1. Presentation of the focus groups.

\begin{tabular}{clc}
\hline Focus Group (FG) & \multicolumn{1}{c}{ Group Characteristics } & Female: Male \\
\hline 1 & $\begin{array}{l}\text { Senior staff from think tanks and trade organisations. } \\
\text { Senior staff/researchers from government agencies, security } \\
\text { studies, trade organisations and network striving to reduce the } \\
\text { business sector's climate impact. } \\
\text { Postgraduate students in sustainability studies and } \\
\text { environmental science. }\end{array}$ & $2: 2$ \\
3 & $4: 1$ \\
\hline Participants represent Swedish or international organisations with their main activities and headquarters in Sweden
\end{tabular}

The participants were recruited by inviting stakeholders of the Mistra Geopolitics research programme, representing Swedish trade organisations, environmental and policy think tanks, research institutes, universities and government agencies. The stakeholders of Mistra Geopolitics have been chosen due to their position as high profile Swedish organisations with global connections and for having a history of engagement in sustainability issues and research. Therefore, these participants could be expected to have knowledge of the 2030 Agenda and geopolitics, as well as being agents of change. Participants of Group 3 were included as representing future experts and practitioners in the field of sustainability. Being in the later stage of master's or doctoral studies, they were at the forefronts of their fields and were expected to obtain positions in business, government, research and non-governmental organisations. A balance between male and female participants was strived for but was, unfortunately, not possible since the position and background of the participants were considered as the most important criteria for the study. The study does not try to encompass all Swedish agents of change nor does it present a general picture of the Swedish society as a whole. It should also be noted that there is a high level of democracy and freedom of speech in Sweden which makes it possible for actors to participate in these kinds of activities and engage in free discussions.

The focus group interviews were moderated by two researchers and were guided by a set of general open-ended questions, posed subsequently during the focus group session, constructed in relation to the aim of this study. The questions concerned which global changes were considered as having effect on Sweden and Swedish actors and sectors, and in what way, currently and within the next 20 years. The participants were also asked about their views on the main geopolitical challenges for sustainable development, for their own activities, for Sweden and the world. The participants engaged in interactions with each other, elaborating on, negotiating and advancing the brought-up issues [45], with minimal interference from the moderators. The focus groups lasted on average $1.5 \mathrm{~h}$ and were audio-recorded and subsequently transcribed verbatim.

A horizontal empirical analysis of all three groups was conducted, scrutinising the whole data set for commonalities and differences in the themes and topics brought up by participants. The unit of analysis was not a specific individual or group, as sense-making is seen as a collective process and dependent on the social context [45]. Thus, utterances should not be decontextualised and each analytical unit therefore cannot be attributed to one single participant. The analysis followed a predefined structure inspired by Marková et al. [44] and was made inductively to give room for unexpected discoveries. The dialogue sequences were first partitioned into topics or topical episodes followed by identification of recurrent topics and, subsequently, themes across the entire material from all the focus groups. Sense-making resources such as analogies, distinctions, metaphors and examples are often used in interactions to make the abstract more concrete and to create and negotiate understanding $[44,46]$. Therefore, specific attention was paid to the participants' use of sense-making resources when identifying themes. The themes were then grouped into larger clusters of themes [44]. 
In the following section, the recurrent topics and themes are presented and, when applicable, related to the sense-making resources used. The recurrent topics are exemplified with excerpts from the focus groups. It should be noted that although participants are quoted individually, the excerpts are the products of conversations taking place in the focus group, and are as such still to be seen as interactive in nature [44].

\section{Results}

In this section the results from the analysis of the focus group material are presented, beginning with the participants' sense-making concerning actors, roles and relations on the geopolitical stage in Section 3.1 (corresponding to the first two research questions). In Sections 3.2 and 3.3, the participants' views on challenges and opportunities, in relation to environmental change and geopolitics, in achieving the 2030 Agenda are presented (corresponding to the third research question).

\subsection{The Geopolitical Stage}

\subsubsection{Actors and Roles}

The focus group discussions displayed contrasting views about who could be seen as the major actors on the geopolitical stage. While participants repeatedly pointed to states as key actors, having an essential role in steering politics and governance, this traditional view was also contested in all focus groups by examples of other actors that have emerged on the geopolitical scene. Cities, individuals, regions and companies were described as increasingly gaining power- "Google has more power than the Swedish government" (FG 2), as one of the participants stated. Swedish companies were described as often acting on an international market and therefore becoming international actors. This wider scope of who is considered a geopolitical actor also reflects a broader understanding of geopolitics itself and its powerplays.

Varying views on who can be considered key geopolitical actors can be seen in relation to ongoing transformations of the global communication landscape, connected to the rapid development and spread of new, digital and social media platforms, breakthroughs in fields such as artificial intelligence and machine learning, and the visualisation of information [2]. A recurrent argument in the focus groups related to the possibilities and dangers that this new global communication landscape brings and how it can empower individuals and groups, that have previously had little means to influence geopolitics, and thereby be an enabler of social change. The increasing level of digitalisation was described as making it possible for a large number of people to connect across the globe. In this line of reasoning, national borders are downplayed, and shared values and interests become stronger than nationality as a unifier. In particular, the "younger generation" was ascribed the tendency to discard national borders. This line of argument can be illustrated by a quotation from one of the focus group discussions, where participants described how individuals in different countries engage in transnational networks, creating borderless communities that share values and fight for a common cause, and thereby jointly becoming a powerful actor:

When it comes to the individual level I think it will become significantly more ... you have more power as an individual in networks ... for example ... 50 million [people] ... direct[ing] the force towards one question in one specific country ... of course it has an effect (FG 2).

Despite several examples of non-state actors gaining geopolitical power, the nation state was not seen as ceasing to exist as a concept or geographic entity in the foreseeable future. The geopolitical stage was rather described as having two kinds of players, the traditional state-centric actors and the non-state actors. In relation to the role of the state, the participants frequently mentioned nationalism and protectionism as growing trends, using examples and stories from current events in different countries to illustrate this, while non-state actors, such as cities, regions, organisations, companies and individuals, 
were described as becoming more globally connected. These developments were accompanied by a portrayal of traditional multilateral organisations, such as the UN and the European Union (EU), becoming weaker as geopolitical actors. Participants anticipated that multilateral organisations might be replaced in the future with new forms of organising cooperation, e.g., bilateral agreements, in a process of downsizing and decentralising power structures.

Notions of consensus, cooperation and finding common goals and synergies were used to discuss relationships between nations and groups in a positive context. Sweden in particular was described as dependent on good relations and cooperation with other nations since the country was seen as a small, open economy. Power relations between regions and states were frequently discussed, such as the relations between China, the USA, North Korea, the EU, Syria and Turkey. The power balance between the USA, China, Russia and Turkey was said to be undergoing change, and a shift in economic power to India and Asia in general was mentioned. Regions such as the Baltic Sea Region, the Nordic countries, the Arctic region and the South China Sea were also discussed in connection with their potential role in the powerplay between states. Political developments and actions within these countries and regions, as well as power relations between them, were mentioned as potentially affecting Swedish actors.

The relationships between actors in the EU and the UN were framed as being filled with tension and conflict and assessed to be on the brink of falling apart, which was denoted as an unwanted development. In contrast, a stronger and more positive relationship between the Nordic countries and the countries around the Baltic Sea was proposed.

\subsubsection{Relations between Actors}

The focus group discussions frequently concerned relations between countries, sectors within countries and groups of people, resulting in several dichotomies, placing actors and groups against each other in opposing positions, and ascribing tensions and frictions to the relations. Concurrently, cooperation, common ground and consensus were said to be important aspects for a thriving society.

Differences in living conditions were discussed as a driver of migration flows, and these differences were expected to increase in the future leading to growing inequalities between those who have and those who have not, the rich and poor, between countries as well as between groups of people within countries. Participants argued that these migration flows might further lead to differences in values between groups and thereby tensions, originating in differences in religious beliefs and culture. However, differences in values were also identified between young and old, where examples like "eating animals or not" (FG 1) were suggested as drivers for the division between the two groups. Differences in values were discussed as being difficult to consolidate and as "tearing society apart" (FG 2) but were also described as constantly changing and dynamic.

As a consequence of increasing urbanisation, rural and urban areas were identified as having conflicting goals and needs, generating winners and losers as economic activities are becoming increasingly concentrated on urban areas. Participants also recognised a gap between citizens based on level of education that could result in inequality in access to power and opportunities and it was pointed out that the well-educated often live in urban areas. These differences were identified by the focus groups as leading to increasing societal polarisation, exemplified by ongoing debates around the value of opinions of different groups of people. Participants further elaborated on a trend of boys underachieving in Swedish schools, which they saw as creating a risk that the majority of the lesser educated will be men, which adds a possible gender aspect to this division.

In the light of these discussions on divisions between groups and the ensuing tensions, the importance of having a common ground in society and reaching consensus on vital issues for a stable and well-functioning nation was emphasised and identified as a future challenge for Swedish society. Governance, business and academia were sectors that were discussed specifically in terms of the need to integrate and work more closely together. Within the national Swedish context, different government departments were reflected on as operating in separate unconnected "silos", working vertically instead of horizontally, which was considered by the participants to be a challenge. 
In contrast, the importance of "diversity", which was not specifically defined by the participants, was frequently raised in connection with people from different cultural backgrounds, ages and abilities. Diversity was discussed as a precondition for prosperity and economic success in a society, which could also entail a diversity of opinions, creating an opposing argument to the discussions on consensus and common ground. It was also mentioned that striving towards consensus in a society can create division between groups - those who are in consensus with each other and those who do not agree with this consensus. However, it should be noted that these two lines of argument, the importance of consensus and common ground vs. the dangers of consensus and the importance of diversity, were never discussed in relation to each other or used by different participants to argue with each other.

\subsection{Linking Environmental Change and Geopolitics}

Across the focus groups, the participants concluded that environmental change can pose a threat to human existence, drawing on the argument that humanity is dependent on functioning ecosystems, both globally and locally. Participants argued that environmental changes are caused by a growing population, increased wealth, unsustainable consumption and the current economic system, processes that interact with each other as well as with ecological systems on several spatial scales, and raised the concern that local actions are causing global change and vice versa.

Several examples of environmental change were brought up in the focus groups, with climate change as a reoccurring topic. The importance and challenges, in the form of negative trade-offs, of adapting to a new climate were stressed. Several participants were optimistic about the future development of fossil-free energy and transportation, and some participants expressed that this challenge would be solved by 2030. However, a negative trade-off of this advancement was raised, whereby the development of renewable energy technology and applications such as electric cars was expected to require large quantities of metals in the future.

In line with this, pollution and degradation of natural resources were two topics that were brought up, both with examples from Sweden and other countries, as exemplified below:

Problems with soil contamination but also this issue of antibiotics will continue, I think-and nano [particles] we know very little about, chemicals and so on ... the chemical market globally is unregulated in many places. And I therefore believe that we will have migration flows perhaps not so much because of war, but more because you want quality ... and to be able to provide a good life for your children. People are fleeing Beijing today because of the air but it could just as well be [because of contaminated] soil (FG 2).

Migration as a means to achieve a better quality of life is described in this excerpt against the backdrop of degraded natural resources caused by emissions of chemicals that we know little about and that are unregulated in some countries, exemplified by the challenge of air quality of Beijing. As natural resources might degrade in quality, participants argued that it could be necessary for people to be mobile to get access to e.g., clean air and water. Ongoing soil degradation in China was also brought up as an example that will have effects on food production and that could force people to move. Climate change was mentioned as a cause of forced movement as some places might not be inhabitable in the future, as one participant reasoned: "As long as there are very large differences in living conditions in different parts of the world, which there will continue to be, there will be migration flows" (FG 1).

A growing world population and an unsustainable "system" were proposed by the participants as drivers of environmental changes:

But I was thinking of this issue of biodiversity ... it will be a challenge whatever we do, because we have $2-3$ billion more people. There will be changes in land use which will automatically lead to reduced biodiversity, especially with the systems we have today. It is very seldom that you see ... another direction so there will be even greater challenges ... and with a larger population, well then we need more natural resources so that will put even 
more strain on the high quality of natural resources in particular ... not least on water and land (FG 2).

Here, one of the participants describes how a future increase in global population will require more land and water resources, which will reduce biodiversity, suggesting a growing population as a cause of these changes, but also attributing responsibility to "the system". While "the system" was never explained in detail, the context suggests that the participant is referring to the current socio-economic system, and implying that this system is not sustainable, since it leads to decreased biodiversity and poor quality of natural resources. Moreover, by stating "It is very seldom that you see ... another direction ... " (FG 2), the participant also implied that it might be difficult, if not impossible, to change the direction of this development and that no such change is anticipated in the near future. Another participant stated that "The economic development is inexorable unless it reaches ... tipping points where the environment collapses around us" (FG 1), which is another example of how the perception of the economic system was linked to environmental change, and that the system will not change unless necessitated by a catastrophe.

It is sort of actually the economic system that we have. It creates this greed and it creates ... the consumption patterns, you might say. Essentially, perhaps, it is the economic system and we talk very little about how to change that. There's the green economy or the circular economy, but it's not actually something new, it has been talked about for many, many years (FG 2).

This quotation exemplifies a recurrent stance where the participants referred to the current economic system as the root cause of environmental change. The reasoning suggested that the economic system has created highly unsustainable consumption patterns and greed which were assumed to spread globally as wealth increases, especially in developing countries, putting even more strain on natural resources. This unsustainable consumption was discussed in relation to "fast consumption" of technological products such as mobile phones and the use of metals in their production. An increased demand for natural resources, such as water, minerals and metals, would have geopolitical implications as conflicts over these resources were seen as gaining increased importance as causes of war: "... more people and more who are better off increase the competition for resources ... which in the long run creates conflicts ... [and] migration flows" (FG 2).

Suggestions that were raised for how to address these challenges included a circular economy with high rates of recycling, which was proposed as being important for future sustainable supplies of minerals and metals. The concept of "the green economy" and the decoupling of economic growth from the use of natural resources were mentioned as necessary future developments, especially in countries where growth in the affluent share of the population and stronger economic development were expected in the near future. The need to change consumption patterns and behaviour was also perceived as being essential. Sweden was frequently described as a small, open economy that is highly integrated with global trade and trade deals. Moreover, a connection was made between Swedish trade, consumption and climate change:

We [Sweden] import a lot of goods for example that are produced in other parts of the world which makes us very vulnerable ... [in terms of] climate change and different weather conditions ... it [adverse impacts of climate change] can happen here but ... we are also affected by [adverse impacts of climate change] what happens there [in parts of the world from which Sweden imports] (FG 3).

A participant here exemplified a recurrent view of Sweden as being dependent on imported goods and thereby vulnerable to changes taking place elsewhere. The focus group discussions were further on concerned with Swedish access to certain goods, for example food, which was expected to be limited in the future since production might be constrained due to a changed climate or otherwise changed environmental conditions. 


\subsection{Geopolitics and the 2030 Agenda}

As presented in the following sections, participants described the relationship between geopolitics and the 2030 Agenda from a number of different perspectives. When discussing both concepts, participants referred to both challenges and opportunities. Figure 1 presents a general overview of these perspectives, indicating the differences in both the number and characteristics of themes that emerged during the focus group discussions, depending on whether the point of departure in an argument was geopolitics or the role of the 2030 Agenda. As seen in Figure 1 some themes were discussed both as opportunities and challenges.

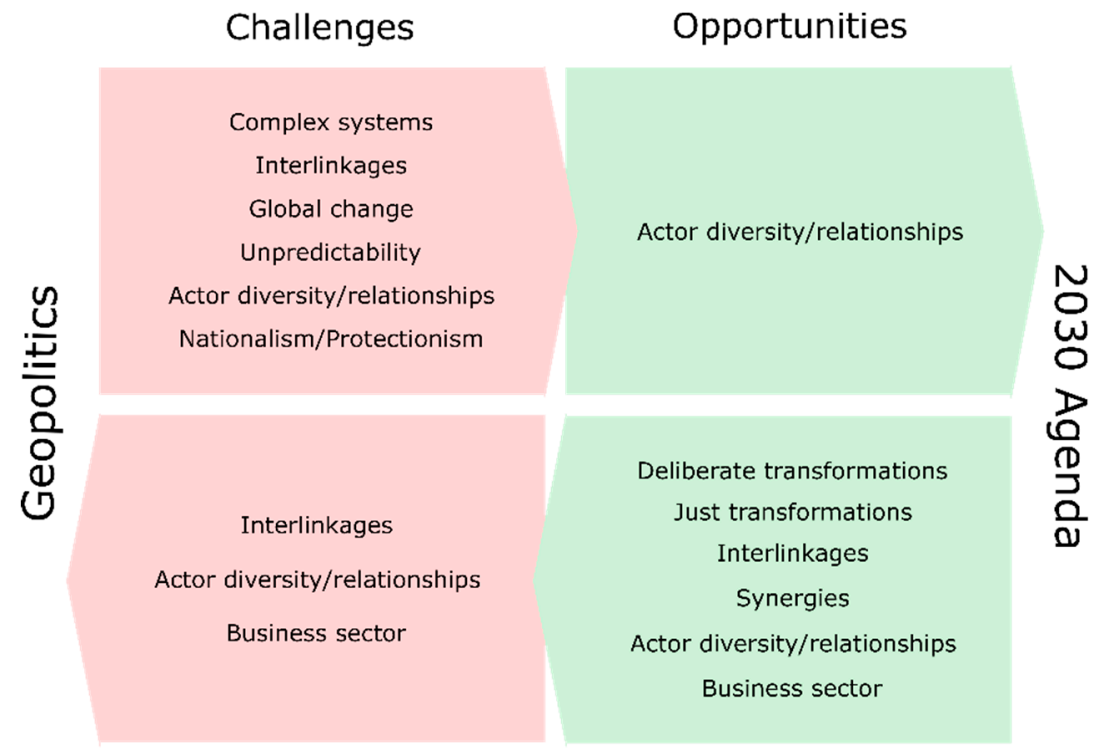

Figure 1. The figure illustrates challenges and opportunities related to the current geopolitical landscape and the 2030 Agenda. Arrows pointing right indicate challenges and opportunities discussed by the participants when using the geopolitical landscape as a point of departure. Arrows pointing left indicate challenges and opportunities discussed by the participants when using the 2030 Agenda and the Sustainable Development Goals as a point of departure.

\subsubsection{Geopolitics as an Obstacle to Achieving the 2030 Agenda}

"I think it is an incredible fuzzy term" (FG 2). "Uncomfortably difficult to grasp" (FG 1). As exemplified by these two quotations from the participants in reference to geopolitics, the concept appeared to be difficult for them to relate to, and was discussed as "abstract", "elusive" and "complex". However, in their collective attempts to make sense of the concept, participants came close to Cohen's definition of geopolitics: "interactions between, on the one hand, geographical settings and perspectives and, on the other, political processes" [3] (p. 16). "Geo" was related to terms that refer to physical settings, such as "nature" and "natural resources", but states and national borders were also tied to this part of the concept. "Politics" was referred to as "governing" and "people", and when combining "geo" with "politics", participants described it as the relationship between people and the physical settings of the planet.

Everything has become so complicated ... it was so simple until 1989. Now it is very fragmented with regional and global and different centers of power. The world has changed quite a lot from simple black and white-"the Russians, the Americans" as it were, into something that still searches for some kind of balance (FG 2).

This excerpt indicates that the insecurity when discussing geopolitics was not solely due to the abstractness of the term itself but was also due to the uncertain and highly dynamic character of the current geopolitical landscape. This participant used the Cold War and the time before the fall of the 
Berlin Wall in 1989, when power relations were more static and easier to predict and understand, as a contrast to the current situation with more diverse actors and fragmented power. This resonates with Cohen's [3] description of a geopolitical transition period since the end of the Cold War.

It was apparent that the relationship between geopolitics and the Sustainable Development Goals was perceived as complex and filled with contradictions. The uncertainties, unpredictability, instability and turmoil of the geopolitical landscape were described as great obstacles to achieving the 2030 Agenda, as illustrated in the following excerpts from the discussions:

When the movement is not fast and linear but just messy. Then it is so incredibly hard to navigate. It is as if the islands are moving by themselves (FG 1).

If I were to ... describe it ... some sort of movement, it's almost like continental plates (laughing) ... it's some game plan change ... it's really like this game changer level and of course stuff like that knocks down all of this. The whole field of game pieces is starting to sort of move ... it's like shaking the table while playing (FG 1).

As illustrated by these quotations, participants drew on the use of metaphors as a sense-making resource to make the complexities of geopolitics more tangible. The quotations illustrate how metaphors relating to movement and geographical settings were used to describe the difficulty in governing when exposed to unpredictable movements in the geopolitical landscape. "Navigate", "shaking", "islands" and "continental plates" were notions and phenomena used to describe global changes that are otherwise difficult to grasp. Recent events in the world were described as "shaking the table" and knocking over the "game pieces" in a boardgame, creating very sudden changes in the distribution of geopolitical power that are impossible to foresee. Making decisions and plans under these circumstances becomes difficult, implying that the participants saw stability and predictability as important factors for successfully achieving the SDGs. As such, these types of metaphors speak to tensions between emergent and deliberate societal transformations, as well as the difficulties of governing complex social systems [2,47-49].

Nationalism and protectionism, exemplified by e.g., "Trumpism”, North Korea's nuclear weapons and Brexit, were highlighted as potential obstacles for achieving the SDGs since these phenomena hinder states from working together, which was said to be crucial. However, state collaborations were not seen as uncomplicated by the participants: "Several different countries are supposed to interact ... having differences ... or facing different threats" (FG 3) as well as having varying priorities and multiple pathways to achieve the 2030 Agenda. Participants raised the question: "how can we interact and agree politically?" (FG 3) amidst these challenges. Participants also deliberated on the risk of conflicts that could arise in relation to the questions of who is causing environmental change and who is responsible for financing transformations towards sustainable societies.

\subsubsection{The 2030 Agenda as an Enabler}

To keep several balls in the air at the same time and connect as well so that we find synergies

... So that it sort of plugs ... so it doesn't start to leak... That we actually find solutions that plug several holes at the same time. I think these global goals provide an opportunity for that (FG 1).

This participant expresses a recurring notion in the focus groups, implying that the challenge of transformation towards sustainability is complex and will require managing several problems, tasks and processes ("balls") simultaneously and not in isolation from each other in order to create synergies and avoid negative trade-offs, described here using metaphors of "leaking" and holes that have to be "plugged". Examples of negative trade-offs linked to transformations of energy and food production systems were raised, the latter described in the following quotation:

"no hunger" as a goal and connect that with "sustainable farming" for example, to not use pesticides and such ... it is possible to produce much more food if using pesticides so it 
becomes tricky ... there will be less [food] production if we would transform [agriculture] $\ldots$ great challenges to reach both goals (FG 3).

Finding synergies was identified as important but also made easier by the SDGs. In general the SDGs were described as powerful in addressing geopolitical challenges by facilitating "work from one agenda together as one planet" (FG 2), bringing together the countries of the world as "Team Earth" (FG 2), working "towards a common goal" (FG 3). However, challenges and possible pitfalls were also recognised in relation to collaboration:

We are talking about bringing people together, but I think there might also be a risk that there will be greater division between different groups when some are pushed away, and some are included in the prioritised group (FG 3).

In the quotation, the creation of divisions between groups and countries is brought up as a potential risk when implementing the SDGs, raising questions of who should be prioritised and who is responsible in deliberate transformations and how to handle associated conflicts.

The metaphor "silos" was used to describe the current situation as characterised by countries, actors, government departments, businesses and sectors working in isolation from each other, which was discussed as obstructing transformation since it is not possible to "lift out the sustainability issue and treat it separately because it crosses over" (FG 2). The SDGs were criticised for being inseparable from each other and always having to be treated with the existing interconnections in mind. It was expressed that this makes them difficult to implement, as it is possible to "start at any end" (FG 1), and one participant wondered how they should cope if they are supposed to see the whole picture at once, arguing that these challenges are too complex to be handled by individuals and organisations. Nonetheless, the SDGs were generally seen as something positive; they "can show how the silos are connected" (FG 2) and if they are thought of "as a filter" (FG 1) for problems, they were described as a great opportunity for transformation at all levels-as one of the participants expressed it, "it's not the UN's goals, it's our goals-all of us" (FG 1). In similar terms, another participant used the following analogy to describe the role of the SDGs:

If you say that the government is an airplane and you sit there in the cockpit and are about to control it, you should have indicators for everything, so you really make decisions that move towards sustainable development. (FG 2)

Here, the participant used the metaphor of movement-in this case a moving airplane that has to be controlled and steered. Just as the dashboard of a plane shows the pilot how and where to steer the plane, the SDGs with their targets and indicators can function as a dashboard indicating how to make decisions that will lead to sustainable societal transformations.

The business sector was described as a powerful geopolitical actor. The participants pointed to the "increased awareness and responsibility, both in the world and in Sweden" (FG 2) of the business community and that sustainability is increasingly becoming a part of "the heart of ... the companies' core business" (FG 2) since it is understood to be essential for "business development and profitability" (FG 1). The business sector was also identified as an important actor in sustainability transformations. In this context, it was proposed that the SDGs offer a platform for Sweden to develop its leadership in the geopolitical landscape, as the country can create "a niche to take the lead" (FG 2) in transformations towards sustainability by for example providing "spearhead solutions" (FG 2), a metaphor meaning that Swedish companies could produce unique, tailored services and products to the rest of the world, which would generate work opportunities in Sweden. This would be possible due to the fact that Sweden has "a business sector that runs far ahead" and "runs fast" (FG 1), and because Swedish companies have the view that "regulations are positive ... because they make companies run faster [on] equal terms" (FG 2). By using the metaphor of "running", Swedish companies are described here as being advanced in terms of sustainability. They are also seen as positive towards being regulated, 
e.g., by climate regulations. However, the participants emphasised that the regulations have to be long term and predictable and must create equal conditions in order to be well received by these companies.

During the focus group discussions, contradictory statements were frequently made and the suitability of Sweden as a leader of sustainability was debated since Sweden has "consumption that is totally unsustainable ... the world's worst" (FG 1). A warning was issued against thinking too highly of Sweden's capacity_- "Sweden alone cannot solve the world's ... problems" (FG 2). An opposing picture of the business community in general was also painted, as it was said to create norms of overconsumption and that companies "do not want to be regulated but would like to move [the responsibility] to the consumer level" (FG 2), meaning that the responsibility for sustainability transformations is placed with the consumer and that regulations are perceived as negative by the business sector.

As outlined in Figure 1, departing from the geopolitical point of view created more challenges than opportunities in the focus group discussions, while the opposite pattern emerged when employing the SDGs as a starting point. However, the discussions were rarely straightforward as the same phenomena were often examined from several perspectives and could entail conflicting ideas and arguments, illustrating a complexity of actors, roles and their agency for societal transformations when linking geopolitics and the 2030 Agenda.

\section{Discussion}

In covering the perspectives of representatives from Swedish businesses, agencies, non-governmental organisations and academia, this study provides insights into how sense-making around geopolitics, environmental change and sustainability can occur. The focus group discussions show the complexity and presence of multiple perceptions, understandings and ways of reasoning when reflecting on sustainability transformations in the light of geopolitical change. The case of Sweden, which is one of the countries with a self-declared ambition for leadership in the 2030 Agenda, indicates the specific need for concerted efforts and the acknowledgement of trade-offs and synergies, as well as new challenges for communication concerning the personal, political and practical spheres of transformations [50].

As this study explored how Swedish change agents make sense of challenges and opportunities for Sweden in achieving the SDGs under geopolitical uncertainty, a number of views were identified. Participants repeatedly emphasised the challenges embedded in working towards achieving the SDGs while navigating emerging geopolitical change. Although the participants related closely to Cohen's definition [4] when discussing the concept of geopolitics, other perspectives were expressed in the focus groups as well. While the metaphors and analogies of board games and game plans that were used point towards geopolitics in a more historical or traditional sense [15], participants' discussions on the roles of a new set of non-state geopolitical actors resonate with a more recent geopolitical discourse, one that aligns with literature highlighting the end of the state as a powerful geopolitical actor and the emergence of new actors, such as cities, companies and groups of civilians [3,23-27]. However, participants also perceived the state as still being a significant player, operating side by side with emerging actors on the geopolitical arena. This might have implications for Swedish national ambitions to take leadership in achieving the 2030 Agenda and indicates a need to include these new actors and relationships. An inclusive approach towards an array of actors has also been expressed by the Swedish government $[37,38]$. Moreover, the sense of fluidity and changing nature of the geopolitical landscape that was a recurrent theme in the focus groups might create uncertainty and challenges for agents of change when striving towards sustainability transformations.

The focus group participants mainly framed future geopolitical landscapes in terms of polarisation, tensions and conflicts between groups. This highlights the need to carefully consider the social dimensions of sustainability transformations, ensuring that actions to achieve sustainability do not threaten the human or ontological security of those who are already vulnerable, as emphasised in the literature on "just transitions" and "just transformations" [2,51,52]. 
One of the recurring points of tension in this study concerned the agency that was ascribed to different groups of actors, as well as their roles and responsibilities. Participants discussed environmental change, in terms of degrading resources, biodiversity and interlinkages between consumption, trade and environmental conditions. New drivers that would influence the agency for sustainability transformations, such as climate change, migration or economics were further identified. Power relations, conflicts and tensions were discussed as influencing the agency of different actors, and also limiting the action spaces for sustainability transformations. On the other hand, examples of new collaborations and consensus between groups and actors were brought up to illustrate ways of increasing the agency for societal transformations and achieving the 2030 Agenda.

One specific area of concern for the participants was Swedish consumption, which was frequently described as being highly unsustainable, causing environmental degradation globally, while Sweden was considered dependent on stable global environmental conditions for food supply due to its high dependency on trade. Participants thereby identified a complex relationship that raises questions about Sweden's responsibility and role as a global leader in the implementation of the 2030 Agenda and about the country's food security and resilience. Swedish food and animal feed imports have been increasing for several decades, with around $50 \%$ of some consumed food commodities currently being imported [53,54], and a recent study suggests possible vulnerabilities for EU countries linked to the exposure to cross-border climate change impacts [55]. In this sense, the vulnerability of Sweden's food supply to geopolitical and environmental changes in other countries might influence the agency of consumers, the food industry and other actors, but also points towards a responsibility linked to transformations of the domestic and global food chains.

Discussions on Sweden's food security might also link to environmental securitization in terms of national food supplies being threatened by environmental change, generating multifaceted challenges and trade-offs in relation to who is in need of being secured, from what threat, by what actors and by what means [6-8]. As the security of Sweden formed the point of departure for the focus group discussions, a state-centric view on security dominated. Global environmental change was described as an imminent threat to Sweden, but not explicitly linked to specific security practices or policies $[5,56]$.

Two strains of narratives emerged from the focus group discussions, underpinned by different types of metaphors and examples, that were indicative for two perspectives on societal transformations: (i) the narrative of the 2030 Agenda, referring to deliberate societal transformations that are seen as being possible to control or steer and that have a direction; and (ii) the narrative of geopolitics, relating to the perception of emergent transformations, which are uncontrollable, and drifting aimlessly towards an unknown future. As both narratives arose frequently in the discussions, the question was how these narratives and the related metaphors and examples are influencing perceptions of societal transformations towards sustainability, as well as the sense of agency to instigate and govern transformative change. Following Lakoff and Johnson [57], we see metaphors as key resources for sense-making that have the power to strongly influence people's understanding of the surrounding world as well as their actions [58]. Thus, metaphors that were used in both narratives might restrict or enable the participants' sense of agency [57]. Most prominently, the metaphors that were used when discussing the 2030 Agenda were frequently related to enabling agency, generating change, creating action and driving change. As such, these metaphors attributed power to the change agents, as well as specific responsibility.

The metaphors relating to the narrative of geopolitics indicated passiveness, inaction, restricting the view of what is possible, and subsequently portraying the "change agents" as powerless. Within this narrative, the lack of control could imply that no responsibility or obligation to act is ascribed to the actors if the challenge is too complex for anyone to have power over it.

The latter view was also present in the focus groups as globalisation and nationalism were discussed as two simultaneous processes, although participants never explicitly discussed the relationship between the two. In previous research, globalisation has been associated with transnationalism and regressing territorial identities [59]. However, it has also been argued by several scholars that 
globalisation and nationalism do not have to exclude each other but can reinforce each other, e.g., globalisation can generate feelings of threat and increase the willingness to protect a nation [3,59-61]. Participants also expressed that the world is in a state of transition and is looking for a new equilibrium after the end of the Cold War, as also suggested by Cohen [3]. However, it should be noted that other scholars argue there is no equilibrium or steady state to be reached, and that, consequently, the world is in constant change [59]. Hereby a notion of a complex geopolitical landscape emerges, encompassing a diverse set of actors and relationships acting on several temporal and spatial scales, which are difficult to define and are potentially contributing to the sense of change and uncertainty that the participants expressed.

Results indicated the particular importance of which perspective is taken when discussing global change, geopolitics and sustainable development. Arguments that took their point of departure in the Sustainable Development Goals generated a more positive, gathering, mobilising and solution-oriented outlook on future geopolitical landscapes, compared to discussions that took their point of departure in the complexity and challenges of the concept of geopolitics. Nevertheless, ambiguities and contradictions in discussions on specific phenomena, such as business, relationships between actors, or values and norms, were prominent. This appeared to be either linked to which perspective or narrative the participants related to (i.e., geopolitics or the Sustainable Development Goals) or indicating that participants had contradicting ideas and opinions on specific issues, which was apparent in discussions on the roles and responsibilities of businesses and the economic system.

\section{Conclusions}

This study set out to explore how Swedish agents of change make sense of challenges and opportunities to achieve the SDGs under geopolitical uncertainty, by identifying geopolitical actors and their agency, roles and responsibility, unfolding relationships between geopolitical actors, and by examining pathways for achieving the 2030 Agenda.

The results of this study pointed towards a few crucial considerations that need to be addressed to facilitate the achievement of the Sustainable Development Goals. First, the identification of different perspectives and implicit trade-offs pointed towards the complexity and different understanding of societal transformations and geopolitical change. This was shown in the variety of actors that were assigned agency to achieve the 2030 Agenda, but also in the relationships that were ascribed to these different actors as well as the drivers that influence and enable change. Similarly, the dual picture of Sweden and Swedish business as forerunner and leader and as a country dependent on imports and generating environmental impacts abroad exemplified the multifaceted roles and responsibilities for high income countries in societal transformations.

Second, this study highlights the importance of communication and the co-creation of knowledge for navigating towards sustainability in changing geopolitical landscapes. The study sheds light on the role of narratives and how these might influence the understandings of societal transformations, as the identified narratives created multiple entry points for dialogues and unfolded different perspectives on opportunities and challenges for achieving the 2030 Agenda. This points towards the need to reflect on how, for instance, cross-sectoral learning and communicative processes can be facilitated to ensure common platforms for deliberative transformations or for responding to emerging transformations, as well as possibilities for seizing the opportunities of the 2030 Agenda.

Author Contributions: Conceptualization, T.-S.N. and V.W.; methodology, K.E., T.-S.N. and V.W.; formal analysis, K.E. and T.-S.N.; investigation, K.E., T.-S.N. and V.W.; writing-original draft preparation, K.E.; writing-review and editing, K.E., T.-S.N. and V.W.; project administration, V.W.

Funding: This publication is a deliverable of MISTRA GEOPOLITICS, which is funded by MISTRA-The Swedish Foundation for Strategic Environmental Research.

Acknowledgments: The authors would like to thank the focus group participants for sharing their perspectives. Thanks are also extended to three anonymous reviewers for constructive comments on an earlier version of this paper. 
Conflicts of Interest: The authors declare no conflict of interest. The funders had no role in the design of the study; in the collection, analyses, or interpretation of data; in the writing of the manuscript, or in the decision to publish the results.

\section{References}

1. UN. Transforming our World: The 2030 Agenda for Sustainable Development; United Nations: New York, NY, USA, 2015.

2. Linnér, B.O.; Wibeck, V. Sustainability Transformations. Agents and Drivers across Societies; Cambridge University Press: Cambridge, UK, 2019.

3. Cohen, S.B. Geopolitics: The Geography of International Relations, 3rd ed.; Rowman \& Littlefield Publisher: Lanham, MD, USA, 2015.

4. Dalby, S. Rethinking geopolitics: Climate security in the anthropocene. Glob. Policy 2014, 5, 1-9. [CrossRef]

5. Trombetta, M.J. Environmental security and climate change: Analysing the discourse. Camb. Rev. Int. Aff. 2008, 21, 585-602. [CrossRef]

6. Dalby, S. Security and Environmental Change; Polity Press: Cambridge, UK, 2009.

7. Hardt, J.N. Environmental Security in the Anthropocene, In Assessing Theory and Practice, 1st ed.; Routledge: London, UK, 2017.

8. McDonald, M. Climate change and security: Towards ecological security? Int. Theory 2018, 10, 153-180. [CrossRef]

9. De Châtel, F. the role of drought and climate change in the Syrian uprising: Untangling the triggers of the revolution. Middle East. Stud. 2014, 50, 521-535. [CrossRef]

10. Stetter, S.; Herschinger, E.; Teichler, T.; Albert, M. Conflicts about water: Securitizations in a global context. Coop. Confl. 2011, 46, 441-459. [CrossRef]

11. Momblanch, A.; Holman, I.P.; Jain, S.K. Current practice and recommendations for modelling global change impacts on water resource in the Himalayas. Water 2019, 11, 1303. [CrossRef]

12. Wine, M.L. Under non-stationarity securitization contributes to uncertainty and Tragedy of the Commons. J. Hydrol. 2019, 568, 716-721. [CrossRef]

13. Dellmuth, L.M.; Gustafsson, M.T.; Bremberg, N.; Mobjörk, M. Intergovernmental organizations and climate security: Advancing the research agenda. Wiley Interdiscip. Rev. Clim. Chang. 2018, 9, e496. [CrossRef]

14. Mach, K.J.; Kraan, C.M.; Adger, W.N.; Buhaug, H.; Burke, M.; Fearon, J.D.; Field, C.B.; Hendrix, C.S.; Maystadt, J.F.; O'Loughlin, J.; et al. Climate as a risk factor for armed conflict. Nature 2019, 571, 193-197. [CrossRef] [PubMed]

15. Koopman, S. Alter-geopolitics: Other securities are happening. Geoforum 2011, 42, 274-284. [CrossRef]

16. Tuathail, G.Ó.; Dalby, S.; Routledge, P. The Geopolitics, Reader; Routledge: London UK, 1998.

17. Hyndman, J. Towards a feminist geopolitics. Can. Geogr. Géographe Can. 2001, 45, 210-222. [CrossRef]

18. Dowler, L.; Sharp, J. A feminist geopolitics? Space Polity 2001, 5, 165-176. [CrossRef]

19. Flint, C. Dying for a "P"? Some questions facing contemporary political geography. Polit Geogr. 2003, 22, 617-620. [CrossRef]

20. Dalby, S. Imperialism, domination, culture: The continued relevance of critical geopolitics. Geopolitics 2008, 13, 413-436. [CrossRef]

21. Sharp, J. Subaltern geopolitics: Introduction. Geoforum 2011, 42, 271-273. [CrossRef]

22. Agnew, J. Geopolitics: Re-Visioning World Politics, 2nd ed.; Routledge: London, UK, 2003.

23. Harrison, J. Rethinking city-regionalism as the production of new non-state spatial strategies: The case of peel holdings Atlantic gateway strategy. Urban Stud. 2014, 51, 2315-2335. [CrossRef]

24. Jonas, A.E.G.; Moisio, S. City regionalism as geopolitical processes: A new framework for analysis. Prog. Hum. Geogr. 2018, 42, 350-370. [CrossRef]

25. Drucker, P. The New Realities; Harper \& Row: New York, NY, USA, 1989.

26. Drucker, P. Post Capitalist Society; Harper Business: New York, NY, USA, 1983.

27. Hardt, M.; Negri, A. Empire; Harvard University Press: Cambridge, MA, USA, 2000.

28. Tuathail, G.Ó. Understanding critical geopolitics: Geopolitics and risk society. J. Strateg. Stud. 1999, 22, 107-124. [CrossRef] 
29. Dalby, S. Recontextualising violence, power and nature: The next twenty years of critical geopolitics? Polit Geogr. 2010, 29, 280-288. [CrossRef]

30. Dalby, S. Environmental geopolitics in the twenty-first century. Altern. Glob. Local Polit 2014, 39, 3-16. [CrossRef]

31. Feola, G. Societal transformation in response to global environmental change: A review of emerging concepts. Ambio 2015, 44, 376-390. [CrossRef] [PubMed]

32. Patterson, J.; Schulz, K.; Vervoort, J.; van der Hel, S.; Widerberg, O.; Adler, C.; Hurlbert, M.; Anderton, K.; Sethi, M.; Barau, A. Exploring the governance and politics of transformations towards sustainability. Environ. Innov. Soc. Transit. 2017, 24, 1-16. [CrossRef]

33. Wibeck, V.; Linnér, B.O.; Alves, M.; Asplund, T.; Bohman, A.; Boykoff, M.T.; Feetham, P.M.; Huang, Y.; Nascimento, J.; Rich, J.; et al. Stories of transformation: A cross-country focus group study on sustainable development and societal change. Sustainability 2019, 11, 2427. [CrossRef]

34. Hajer, M.; Nilsson, M.; Raworth, K.; Bakker, P.; Berkhout, F.; de Boer, Y.; Rockström, J.; Ludwig, K.; Kok, M. Beyond cockpit-ism: Four insights to enhance the transformative potential of the sustainable development goals. Sustainability 2015, 7, 1651-1660. [CrossRef]

35. Swilling, M.; Hajer, M. Governance of urban transitions: Towards sustainable resource efficient urban infrastructures. Environ. Res. Lett. 2017, 12,1-8. [CrossRef]

36. Alrøe, H.F.; Sautier, M.; Legun, K.; Whitehead, J.; Noe, E.; Moller, H.; Manhire, J. Performance versus values in sustainability transformation of food systems. Sustainability 2017, 9, 332. [CrossRef]

37. Government of Sweden. Sweden and the 2030 Agenda-Report to the UN High Level Political Forum 2017 on Sustainable Development. Available online: https:/www.government.se/49f428/ contentassets/400a118a14b94750a61e42b620a9def9/sweden-and-the-2030-agenda--report-to-the-un-highlevel-politicalforum-2017-on-sustainable-development.pdf (accessed on 1 July 2019).

38. Ministry of the Environment and Energy. The Goal Is a Fossil-Free Sweden. Available online: https://www.government.se/contentassets/ef6483a702fd4d1a860e7ca7f4b6fe70/faktablad_fossil_free_ sweden_en_webb.pdf (accessed on 1 July 2019).

39. Global Footprint Network. Global Footprint Network National Footprint Accounts 2019 Edition. Available online: http://data.footprintnetwork.org (accessed on 1 July 2019).

40. Mauser, W.; Klepper, G.; Rice, M.; Schmalzbauer, B.S.; Hackmann, H.; Leemans, R.; Moore, H. Transdisciplinary global change research: The co-creation of knowledge for sustainability. Curr. Opin. Environ. Sustain. 2013, 5, 420-431. [CrossRef]

41. Vaughn, S.; Shay Schumm, J.; Sinagub, J. Focus Group Interviews in Education and Psychology; Sage: Newbury Park, CA, USA, 1996.

42. Bakhtin, M.M. Speech Genres and Other Late Essays; Emerson, C., Holquist, M., Eds.; Texas University Press: Austin, TX, USA, 1986.

43. Linell, P. Rethinking Language, Mind and World Dialogically: Interactional and Contextual Theories of Human Sense-Making; Information Age Publishing: Charlotte, NC, USA, 2009.

44. Marková, I.; Linell, P.; Grossen, M.; Orvig, A.S. Dialogue in Focus Groups: Exploring Socially Shared Knowledge; Equinox Publishing Ltd.: London, UK, 2007.

45. Wilkinson, S. Focus group methodology: A review. Int. J. Soc. Res. Methodol. 1998, 1, 181-203. [CrossRef]

46. Billig, M. Arguing and Thinking. A Rhetorical Approach to Social Psychology; Cambridge University Press: Cambridge, UK, 1987.

47. Flood, R.L. Rethinking the Fifth Discipline: Learning within the Unknowable; Routledge: London, UK, 2002.

48. Miller, J.H.; Page, S. Complex Adaptive Systems: An Introduction to Computational Models of Social Life; Princeton University Press: Princeton, NJ, USA, 2007.

49. Westley, F.; Olsson, P.; Folke, C.; Homer-Dixon, T.; Vredenburg, H.; Loorbach, D.; Thompson, J.; Nilsson, M.; Lambin, E.; Sendzimir, J.; et al. Tipping toward sustainability: Emerging pathways of transformation. Ambio 2011, 40, 762-780. [CrossRef] [PubMed]

50. O’Brien, K.; Sygna, L. Responding to climate change: The three spheres of transformation. Proc. Transform. Chang. Clim. 2013, 16, 23.

51. Swilling, M.; Annecke, E. Just Transitions: Explorations of Sustainability in an Unfair World; United Nations University Press: Tokyo, Japan, 2012. 
52. Sartor, O. Implementing Coal Transitions: Insights from Case Studies of Major Coal-Consuming Economies; IDDRI and Climate Strategies: Paris, France, 2018.

53. Deutsch, L.; Folke, C. Ecosystem subsidies to Swedish food consumption from 1962 to 1994 . Ecosystems 2005, 8, 512-528. [CrossRef]

54. Lannhard Öberg, A. Marknadsrapport NÖT-Utvecklingen till och med 2018 (Market Report Beef-Development until 2018); The Swedish Board of Agriculture: Jönköping, Sweden, 2019.

55. Benzie, M.; Carter, T.R.; Carlsen, H.; Taylor, R. Cross-border climate change impacts: Implications for the European Union. Reg. Environ. Chang. 2019, 19, 763. [CrossRef]

56. Wine, M.L.; Davison, J.H. Untangling global change impacts on hydrological processes: Resisting climatization. Hydrol. Process. 2019, 2148-2155. [CrossRef]

57. Lakoff, G.; Johnson, M. Metaphors We Live BY; The University of Chicago Press: Chicago, IL, USA, 1980.

58. Nerlich, B.; Jaspal, R. Metaphors We Die BY? Geoengineering, metaphors, and the argument from catastrophe. Metaphor Symb. 2012, 27, 131-147. [CrossRef]

59. Antonsich, M. Nation and Nationalism. In The Wiley Blackwell Companion to Political Geography; Agnew, J.A., Mamadouh, V., Secor, A., Sharp, J., Eds.; Wiley-Blackwell: Chichester, UK, 2015; pp. 297-310.

60. Biswas, S. W(h)ither the nation-state? National and state identity in the face of fragmentation and globalisation. Glob. Soc. 2002, 16, 175-198. [CrossRef]

61. Antonsich, M. National identities in the age of globalisation: The case of Western Europe. Natl. Identities 2009, 11, 281-299. [CrossRef]

(C) 2019 by the authors. Licensee MDPI, Basel, Switzerland. This article is an open access article distributed under the terms and conditions of the Creative Commons Attribution (CC BY) license (http://creativecommons.org/licenses/by/4.0/). 